\title{
Contribuições da Teoria dos Registros de Representação Semiótica para a análise do capítulo de funções de um livro didático
}

\author{
Contributions from Theory of Semiotics Representation Registers to the \\ function chapter analysis of a textbook
}

\author{
Izabella Batista Silva \\ Giovani Prando \\ Jorge Henrique Gualandi
} \begin{abstract}
identificar e analisar os registros de representação que o livro traz no texto explicativo do capítulo escolhido e de que modo ocorre a coordenação entre eles. Ao final, concluímos que a forma como ocorre a articulação entre os registros de representação exibidos no livro favorece a compreensão do objeto matemático funções, visto que os variados registros de representação são utilizados simultaneamente ao abordar cada parte da explicação.
\end{abstract}

Resumo: Este trabalho apresenta uma análise de um capítulo do livro didático do Ensino Médio "Matemática: Contexto e Aplicações", de Luiz Roberto Dante, sobre o conteúdo de funções, fundamentada em alguns pressupostos da Teoria dos Registros de Representação Semiótica. A obra escolhida para a análise é o volume 1 de uma coleção aprovada pelo Programa Nacional do Livro Didático (PNLD 2018). Para isso, realizou-se um estudo de caráter qualitativo a partir da Teoria dos Registros de Representação Semiótica de Raymond Duval, no qual se objetivou

Palavras-chave: Registros de Representação Semiótica. Funções. Livro didático.

Abstract: This paper presents an analysis of a chapter of Luiz Roberto Dante's high school textbook "Mathematics: Context and Applications" on the content of functions, based on some assumptions of the Semiotic Representation Records Theory. The work chosen for the analysis is volume 1 of a collection approved by the National Textbook Program (PNLD 2018). For this, a qualitative study was carried out from Raymond Duval's Theory of Semiotic Representation Records, which aimed to identify and analyze the representation records that the book brings in the explanatory text of the chosen chapter and how it occurs the coordination between them. In the end, we conclude that the way the articulation between the representation records displayed in the book occurs favors the understanding of the mathematical object functions, since the various representation records are used simultaneously when approaching each part of the explanation.

Keywords: Semiotics Representation Registers. Functions. Textbook.
Izabella Batista Silva Licenciada em Matemática (IFES). Professora da Secretaria Municipal de Educação de Presidente Kennedy. Espírito Santo, Brasil.

iD orcid.org/0000-0002-2594-3123

\izabella-09@hotmail.com

Giovani Prando Mestre em Matemática (UFES). Instituto Federal de Educação, Ciência e Tecnologia do Espirito Santo (IFES), campus Aracruz. Espirito Santo, Brasil.

(iD) orcid.org/0000-0002-7421-4824

$\bowtie$ giovanimatufes@yahoo.com.br

Jorge Henrique Gualandi Doutor em Educação Matemática (PUC-SP). Professor do Instituto Federal de Educação, Ciência e Tecnologia do Espírito Santo (IFES), unidade Cachoeiro de Itapemirim. Espírito Santo, Brasil.

(iD) orcid.org/0000-0002-0302-7650

$\bowtie$ jhgualandi@gmail.com

Recebido em 03/09/2019 Aceito em 19/10/2019 Publicado em 20/03/2020 


\section{Introdução}

O entendimento da linguagem algébrica é de extrema importância para a compreensão e interpretação de problemas matemáticos. De acordo com as Orientações Complementares aos Parâmetros Curriculares Nacionais (BRASIL, 2002) é possível modelar situações-problema e estudar fenômenos dentro e fora da Matemática usando argumentos algébricos, em especial, as funções. Analisando a Base Nacional Comum Curricular, é possível observar que a introdução desse conteúdo inicia no Ensino Fundamental e é aprofundada até o final do Ensino Médio, dispondo de grande espaço nos currículos e, consequentemente, nos livros didáticos. Assim, entendemos que o estudo de funções abrange um dos pontos altos do ensino da Matemática na educação básica.

Buscou-se analisar como o objeto matemático funções é abordado em um capítulo de um livro didático do Ensino Médio. Para isso, foi escolhido o volume 1 da coleção "Matemática: Contexto e Aplicações", obra aprovada pelo Programa Nacional do Livro Didático 2018 (BRASIL, 2017).

Para realizar o trabalho proposto, foi selecionado o capítulo intitulado "Funções", buscando identificar e analisar quais registros de representação que o livro traz na explicação do capítulo e como ocorre a coordenação entre esses registros, visto que, para Duval, a articulação entre os registros de representação semiótica implica a compreensão matemática.

Esse trabalho embasou-se em alguns pressupostos da Teoria dos Registros de Representação Semiótica de Raymond Duval (1999, 2003, 2012) a qual enfatiza a importância da utilização de diferentes registros de representação e a articulação entre eles, para que o aluno compreenda os objetos matemáticos. Essa teoria tem se mostrado um "importante instrumento de pesquisa, no estudo da complexidade de aprendizagem matemática" (MACHADO, 2003, p. 8).

\section{Referencial teórico}

É importante estabelecer relações da Matemática com ela mesma, ou seja, entre a Geometria, a Álgebra e a Aritmética. Isso é relevante para que os alunos vivenciem momentos em que os conteúdos matemáticos possam estar interligados (GUALANDI, 2016, p. 15). Com 0 aprendizado da Matemática é possível interpretar várias situações-problema e realizar cálculos de diversas naturezas. Em relação ao estudo de funções, particularmente 
permite ao aluno adquirir a linguagem algébrica como a linguagem das ciências, necessária para expressar a relação entre grandezas e modelar situações-problema, construindo modelos descritivos de fenômenos e permitindo várias conexões dentro e fora da própria matemática". (BRASIL, 2002 p. 121).

Assim, o aprendizado de funções é significativo para que o aluno desenvolva sua capacidade de generalização e abstração, necessária para o estudo e interpretação de situações dentro e fora da Matemática, como também para a resolução de problemas.

Nesse estudo, definiremos funções segundo Courant e Robbins (2000):

É possível que cada valor de uma vaiável $X$ esteja associado um valor bem definido de uma outra variável $U$. Então $U$ é chamado de função de $X$. A maneira pela qual $U$ está relacionado com $X$ é expressa por um símbolo tal como $U=F(X)$, leia-se " $F$ de $X$ " (p. 333).

Um exemplo de funções é a relação entre triângulos e o comprimento do seu perímetro: "Se S é o conjunto de todos os triângulos $X$ no plano, uma função $F(X)$ pode ser definida atribuindose a cada triângulo $X$ o comprimento $U=F(X)$ de seu perímetro; $T$ será 0 conjunto de todos os números positivos" (COURANT e ROBBINS, 2000, p. 333).

As Orientações Curriculares para o Ensino Médio sugerem o uso da linguagem materna ao interpretar uma função dada de forma algébrica, incentivando a exploração de forma qualitativa entre duas grandezas distintas, além de destacar a importância da representação gráfica. É explicado que "a elaboração de um gráfico por meio da simples transcrição de dados tomados em uma tabela numérica não permite avançar na compreensão do comportamento das funções" (BRASIL, 2006, p. 72).

É necessária a compreensão das situações propostas por meio das funções, não permitindo que 0 aprendizado se resuma à transcrição de dados, mas, sim, que os gráficos e tabelas sejam uma maneira de representar as ideias entendidas. Segundo D'Amore, Pinilla e lori (2015), para fazer alusão a qualquer conceito matemático, deve-se fazer uso de suas representações, visto que não há acesso diretamente sensível a tais objetos. Isso evidencia a necessidade de 0 aluno transitar entre as diferentes formas de representação de um objeto matemático, nesse caso, as funções.

Ao analisar o conhecimento matemático é preciso considerar "a necessidade intrínseca do uso das representações semióticas e a variedade dos registros utilizados em Matemática" (BRANDL, 2011, p. 16). Vale ressaltar que as representações semióticas "são produções 
constituídas pelo emprego de signos pertencentes a um sistema de representações que tem inconvenientes próprios de significação e de funcionamento" (DUVAL, 2012, p. 269). Elas são essenciais para a vida cognitiva do pensamento, desempenhando grande papel na comunicação, no desenvolvimento das representações mentais e produção de conhecimento. Um registro de representação semiótica é "um sistema semiótico que tem as funções cognitivas fundamentais no funcionamento cognitivo consciente, sendo uma maneira típica de representar um objeto matemático, ou um problema, ou uma técnica" (DUVAL, 1999 apud ALMOULOUD, 2007, p. 80).

As transformações dos registros de representações se dividem em dois tipos: os tratamentos e as conversões. 0 tratamento é a transformação de uma representação no mesmo registro onde foi formada, enquanto a conversão é a transformação de uma representação em outro tipo de registro (DUVAL, 2012). Um exemplo de conversão é "passar da escrita algébrica de uma equação à sua representação gráfica" (DUVAL, 2003, p. 16). Já os tratamentos podem ser exemplificados por

efetuar um cálculo ficando estritamente no mesmo sistema de escrita ou de representação dos números; resolver uma equação ou um sistema de equações; completar uma figura segundo critérios de conexidade e de simetria" (DUVAL, 2003, p. 16).

É importante destacar que um objeto não se limita às suas representações, mas sim, essas representações simbolizam um mesmo conceito, cada uma com suas particularidades e características. Para Duval (2012, p. 270), "a coordenação de muitos registros de representação aparece, fundamentalmente, para uma apreensão conceitual de objetos". Destaca-se a importância da conversão dos sistemas de representações, visto que "a compreensão em Matemática implica a capacidade de mudar de registro" (DUVAL, 2003, p. 21). Portanto, é fundamental a articulação entre o maior número de registros possíveis para uma melhor compreensão do objeto matemático.

Muitas vezes, realizar a transformação do registro de um objeto — tanto por tratamento, quanto por conversão - permite ao sujeito uma compreensão mais ampla e simples da questão estudada. Por exemplo, a função $f(x)=x^{2}+3 x+2$ também pode ser representada por $f(x)=(x+1) \cdot(x+2)$. Nesse segundo caso, o tratamento do objeto matemático facilita a obtenção das raízes. E realizando a conversão entre gráficos e equações, 
gráfico (inclinação, interseção com os eixos etc.) e, de outro, os valores escalares da equação (coeficientes positivos ou negativos, maior, menor ou igual a 1 etc.) [...]" (DUVAL, 2003, p.17)

Assim como a grande maioria dos objetos matemáticos, as funções não são diretamente acessíveis e observáveis. É necessário um sistema de representações para compreender a ideia por trás do conceito. Segundo Almouloud (2007, p. 80), as funções podem ser representadas "por quatro registros de representação semiótica: registro de tabelas, das fórmulas algébricas, gráfico e simbólico"; o registro gráfico inclui também o registro de desenho. Além desses, temos a representação na língua natural (linguagem discursiva) e a representação icônica, por meio de diagramas.

As Orientações Educacionais Complementares aos Parâmetros Curriculares Nacionais destacam a importância de se "dominar códigos e nomenclaturas da linguagem matemática, compreender e interpretar desenhos e gráficos e relacioná-los à linguagem discursiva" (BRASIL, 2002, p. 112). Aborda ainda as habilidades propostas para a unidade temática das funções, sendo que algumas delas envolvem "associar diferentes funções aos seus gráficos correspondentes [...]" e "[...] ler e interpretar diferentes linguagens e representação envolvendo variações de grandezas" (BRASIL, 2002, p. 123). Isso reforça a importância da compreensão e do domínio de diferentes sistemas de representação, para que seja possível o pleno entendimento de funções.

Consideramos significativa a presença das variadas formas de registros de representação no livro didático, pois entendemos que esse recurso

é uma das principais formas de documentação e consulta empregados por professores e alunos. Nessa condição, ele às vezes termina por influenciar o trabalho pedagógico e o cotidiano da sala de aula (BRASIL, 2003, p. 10).

Muitas vezes, é o único recurso que o aluno possui fora de sala de aula para acompanhar o processo de aprendizagem. Ele "se alicerça como elemento da cultura escolar, organizando a seleção de conteúdos, interferindo e guiando as práticas pedagógicas e contribuindo, ao seu modo, para as formas de construção do conhecimento no ambiente escolar" (TEIXEIRA, 2014, p. 39). O livro didático se torna, então, um recurso extremamente importante, tanto dentro, quanto fora da sala de aula, visto que pode ser utilizado em ambos os momentos.

As Orientações Curriculares para o Ensino Médio (2006, p. 86) esclarecem que o "livro didático vem assumindo, há algum tempo, o papel de única referência sobre o saber a ser ensinado", e desaconselha seu uso desse modo, mas sim como um 'recurso a mais'. Assim sendo, 
o livro didático tem sua importância condicionada ao uso que o professor faça dele (ROMANATTO, 2004).

O Guia do PNLD 2018 incentiva a apresentação do conteúdo de funções como relação entre grandezas variáveis sendo seguida pela sistematização como uma correspondência entre elementos de dois conjuntos, uma vez que "é relevante abordar diferentes representações tabelas, gráficos, fórmulas algébricas - estabelecendo-se relações entre elas" (BRASIL, 2017, p. 26).

Desse modo, é pertinente realizar uma análise de livros didáticos, usando os pressupostos da Teoria dos Registros de Representação Semiótica.

\section{Metodologia}

A investigação foi realizada em um livro didático do Ensino Médio aprovado pelo PLND 2018, intitulado "Matemática: Contextos e Aplicações", de autoria de Luiz Roberto Dante. $O$ critério para escolha do livro citado foi em razão do mesmo ser adotado nas escolas públicas de Ensino Médio do município de Cachoeiro de Itapemirim (ES). Trata-se da terceira edição de uma coleção da editora Ática, composta por livros para todos os anos do Ensino Médio. Foi publicado em 2016 e trata-se do volume 1 do exemplar do aluno.

Segundo Bicudo (2014) a pesquisa qualitativa foca em experiências individuais, descrição de situações, trabalhando com especificidades contextualizadas e envolvendo a individualidade e descrição pormenorizada do observado. Visando analisar as particularidades de um capítulo do livro didático, esse estudo se mostra de caráter qualitativo com embasamento teórico nos Registros de Representação Semiótica de Raymond Duval.

A análise foi realizada no capítulo 2, intitulado "Funções", que possui 24 páginas e está incluso na unidade 1, denominada "Números e Funções". É dividido em 10 subtítulos, que são: Um pouco da história das funções; Explorando intuitivamente a noção de função; A noção de função por meio de conjuntos; Domínio, contradomínio e conjunto imagem; Estudo do domínio de uma função real; Coordenadas cartesianas; Gráfico de uma função; Função crescente e função decrescente: analisando gráficos; Função injetiva, sobrejetiva e bijetiva; e Funções e sequências. No final do capítulo há sessões destinadas a exercícios de vestibulares e Exame Nacional do Ensino Médio (ENEM), intituladas "Pensando no Enem" e "Vestibulares de Norte a Sul". 
Para realizar a análise, foram contabilizados cada um dos registros de representação de funções e observado como o autor discorria sobre o conteúdo, realizando ou não a conversão entre registros e se essa coordenação entre eles possibilita a compreensão do objeto. Ressaltamos que a análise foi direcionada apenas ao texto explicativo, de forma a não incluir os exercícios e atividades propostas pelo livro.

\section{Análise}

O capítulo inicia com uma contextualização histórica das funções e do modo como era intuitivamente usada. Aborda Cláudio Ptolomeu - um cientista do século II, que relacionou os ângulos de uma semicircunferência com diâmetro de 120 unidades, ao comprimento de sua corda. Para isso, o livro traz a explicação em linguagem natural, em registro de tabela e em registro gráfico, em que mostra a representação gráfica de uma semicircunferência com seu ângulo a e sua corda L, conforme observado na Figura 1.

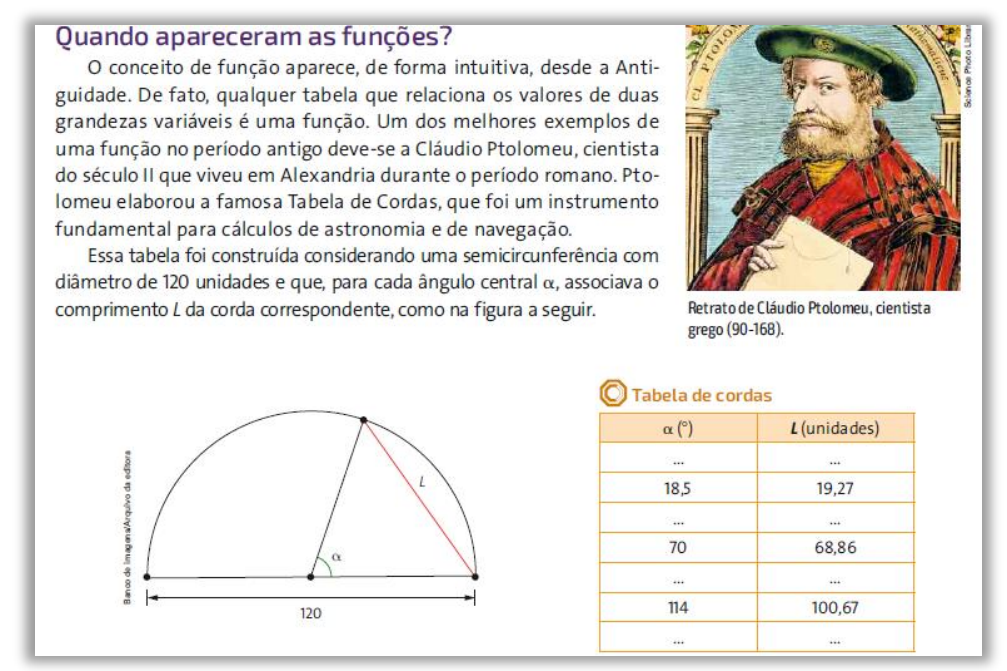

Figura 1: Relação dos ângulos de uma semicircunferência com a corda (DANTE, 2016, p. 41)

Em seguida, e ainda em linguagem natural, é abordada a definição de função por Jean Bernoulli e Gottfried Leibniz, cujo conceito é bem próximo ao de Courant e Robbins (2000). Após isso, fala-se de Leonard Euler e sua representação de função no registro simbólico, como $f(x)$, e em sequência, do matemático Lejune Dirichlet com sua definição em linguagem natural, em que 0 mesmo denomina as variáveis como dependentes e independentes. Por fim, é abordada a definição por meio de conjuntos, criada no final do século XIX, representando as funções pela língua natural, pela linguagem algébrica e pelo diagrama, conforme observado na Figura 2. 


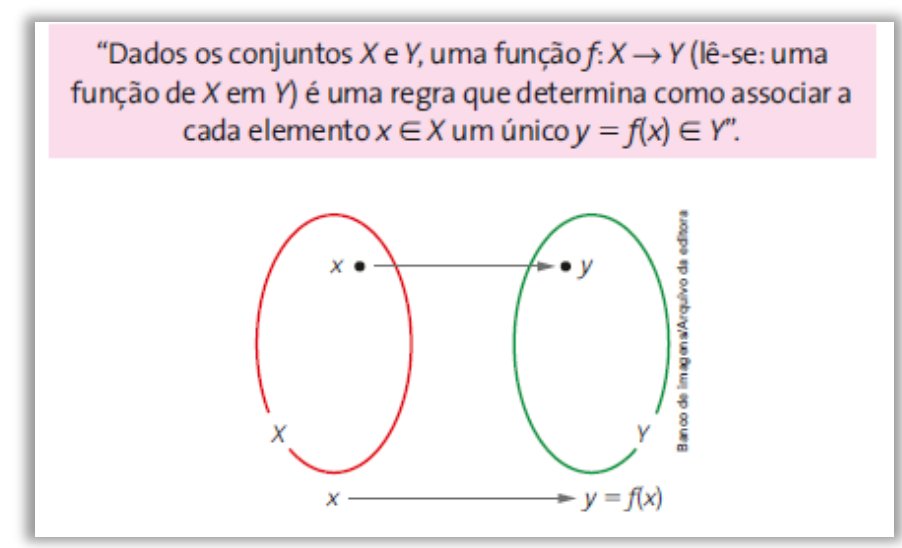

Figura 2: Definição formal do conceito de funções por meio de conjuntos (DANTE, 2016, p. 42)

No subtítulo "Explorando intuitivamente a noção de função", são apresentadas situações que tem relação com funções. Nessa parte é inserido o conceito de variáveis dependentes e independentes. Na Figura 3 é possível observar um exemplo que relaciona a medida do lado de um quadrado com seu perímetro.

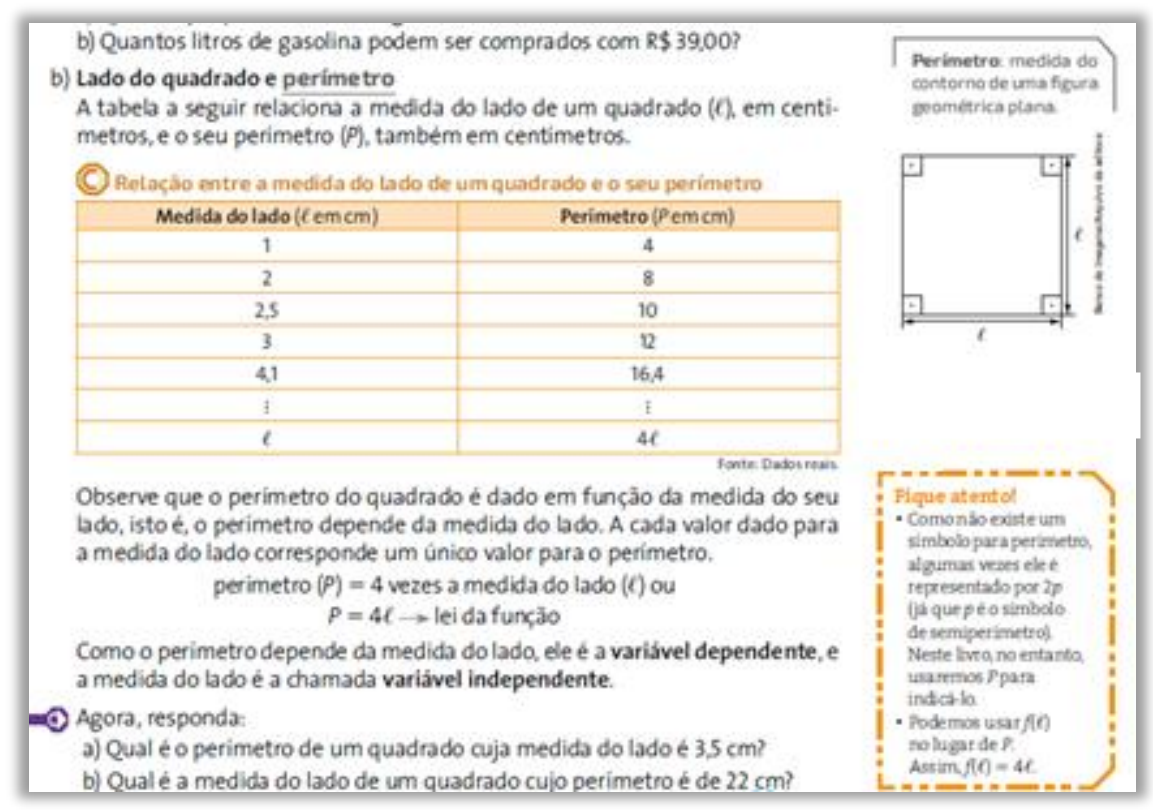

Figura 3: Exemplo da abordagem de funções (DANTE, 2016, p. 45)

As outras três situações seguem o mesmo padrão do exemplo. São abordadas as relações entre os litros de gasolina comprados com o preço a ser pago, cada número e seu valor dobrado e o tempo gasto em uma viagem de carro com a distância percorrida. De forma similar ao exemplo, é usado o registro de tabelas com a sintetização em expressões algébricas.

É interessante destacar que o livro não se restringe a utilizar a notação $f(x)$. Em cada exemplo traz uma abordagem diferente — como $\mathrm{P}, \mathrm{N}$ e D - para representar a ideia, e ao lado 
de cada situação explica que existe a notação padrão, como mostrado na Figura 3. Assim, o livro realiza um tratamento de um registro simbólico visando que o aluno tenha uma compreensão mais ampla das notações simbólicas e saiba, futuramente, associar as diferentes representações às funções.

Após explorar a noção intuitiva, o livro insere a ideia de funções por meio de conjuntos. 0 primeiro exemplo aparece com o uso de linguagem natural, tabela e representação icônica (diagrama). A explicação é sintetizada com uma expressão algébrica do exemplo.

Nos outros exemplos é mostrado por meio do diagrama e de linguagem natural o porquê de serem ou não serem funções. Ao final do subtítulo é apresentada a definição de funções relacionadas a conjuntos, conforme o quadro 4 :

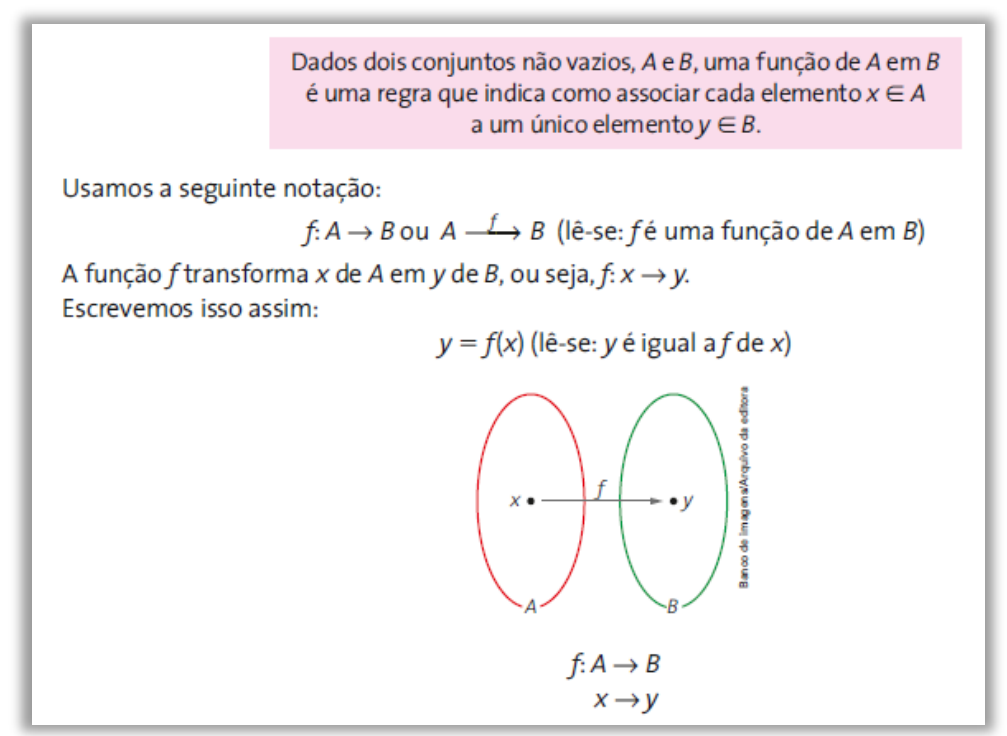

Figura 4: Definição formal de funções por meio de conjuntos (DANTE, 2016, p. 49)

Nos tópicos seguintes, o livro apresenta a definição de domínio, contradomínio e imagem, além de abordar o estudo do domínio de uma função real. As definições são apresentadas, em sua maior parte, pela linguagem natural e sintetizadas ao final, pelo registro simbólico. É utilizado também o registro icônico para expressar a dependência entre as variáveis. É feito o uso de exemplos, utilizando os mesmos registros de representação.

Ocorre, dessa forma, a sistematização como uma correspondência entre elementos de dois conjuntos, como sugere o PNLD 2018, por meio da linguagem natural, registro simbólico e registro icônico. Além disso, é importante destacar que a definição por meio de conjuntos já tinha sido abordada no início do capítulo, na contextualização histórica. Dessa forma, é possível associar a história da Matemática, com a Matemática que temos hoje. 
Ao falar sobre coordenadas cartesianas, as definições são dadas pela linguagem natural com auxílio de notação simbólica. Introduz as definições de eixos ortogonais com linguagem natural e registro gráfico. Os quadrantes são delimitados com o auxílio do registro simbólico, ilustrado na Figura 5.

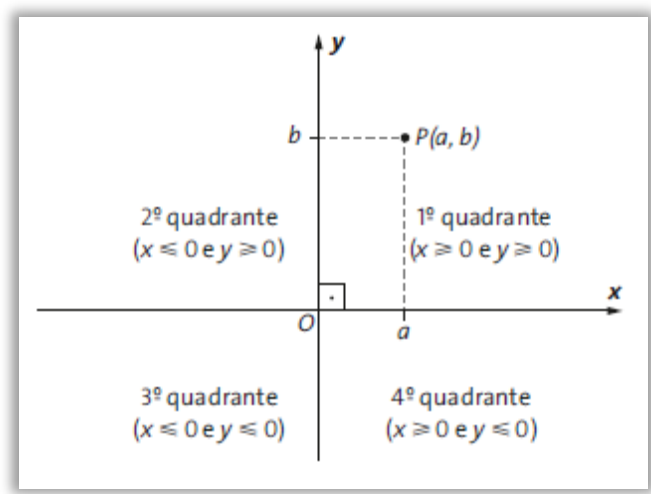

Figura 5: Plano cartesiano com representação simbólica (DANTE, 2016, p. 52)

O livro traz um exemplo de como localizar pontos no plano cartesiano e, para isso, utiliza linguagem natural e registro gráfico. Ao falar de distância entre dois pontos, a ideia é construída pela linguagem natural, desenvolvida com a ajuda do registro simbólico e sintetizada com a expressão algébrica, além de apresentar um gráfico do que é enunciado no texto.

O livro aborda também a equação de uma circunferência. Faz uma introdução com linguagem natural e traz, em sequência, o registro icônico, de uma circunferência de raio r. $\mathrm{A}$ construção das ideias é feita por linguagem natural junto ao registro simbólico, auxiliada pelo gráfico da circunferência. Por fim, sintetiza a explicação com a equação da circunferência e sugere que 0 aluno verifique como será essa equação quando o centro da circunferência estiver na origem. Assim, ao realizar o tratamento do registro algébrico, o aluno poderá concluir que a expressão algébrica é simplificada, tornando-se uma equação para um caso particular.

Apenas nesse subcapítulo o registro de representação gráfica, incluindo o registro de desenhos, ocorre seis vezes, acompanhando sempre a explicação do autor que é feita em linguagem natural com 0 auxílio de fórmulas e notações simbólicas. 0 livro aborda diferentes representações, fazendo a conversão entre os registros, de forma a possibilitar a apreensão conceitual do aluno em relação ao plano cartesiano. Assim, propicia ao aluno o domínio de códigos e nomenclaturas da linguagem matemática e a compreensão e interpretação de desenhos e gráficos e relacionando à linguagem discursiva, como propõe as Orientações Educacionais Complementares aos Parâmetros Curriculares Nacionais (BRASIL, 2002). 
No subtítulo "Gráfico de uma função", as ideias são inseridas por meio de notação simbólica com o auxílio de linguagem natural, e é apresentado um gráfico com as informações. Em seguida, é determinado quando um conjunto de pontos corresponde ao gráfico de uma função. Faz isso em linguagem natural com auxílio de representações simbólicas, e traz exemplos utilizando o registro gráfico.

Ao explicar como construir um gráfico, o autor traz um "passo a passo" em língua natural com auxílio de notações simbólicas e três exemplos, aos quais as funções são apresentadas com sua expressão algébrica, especificando por meio de notação simbólica os domínios. Utilizando uma tabela, o livro encontra os pares ordenados da função, e depois os representa graficamente, como exemplificado na Figura 6.

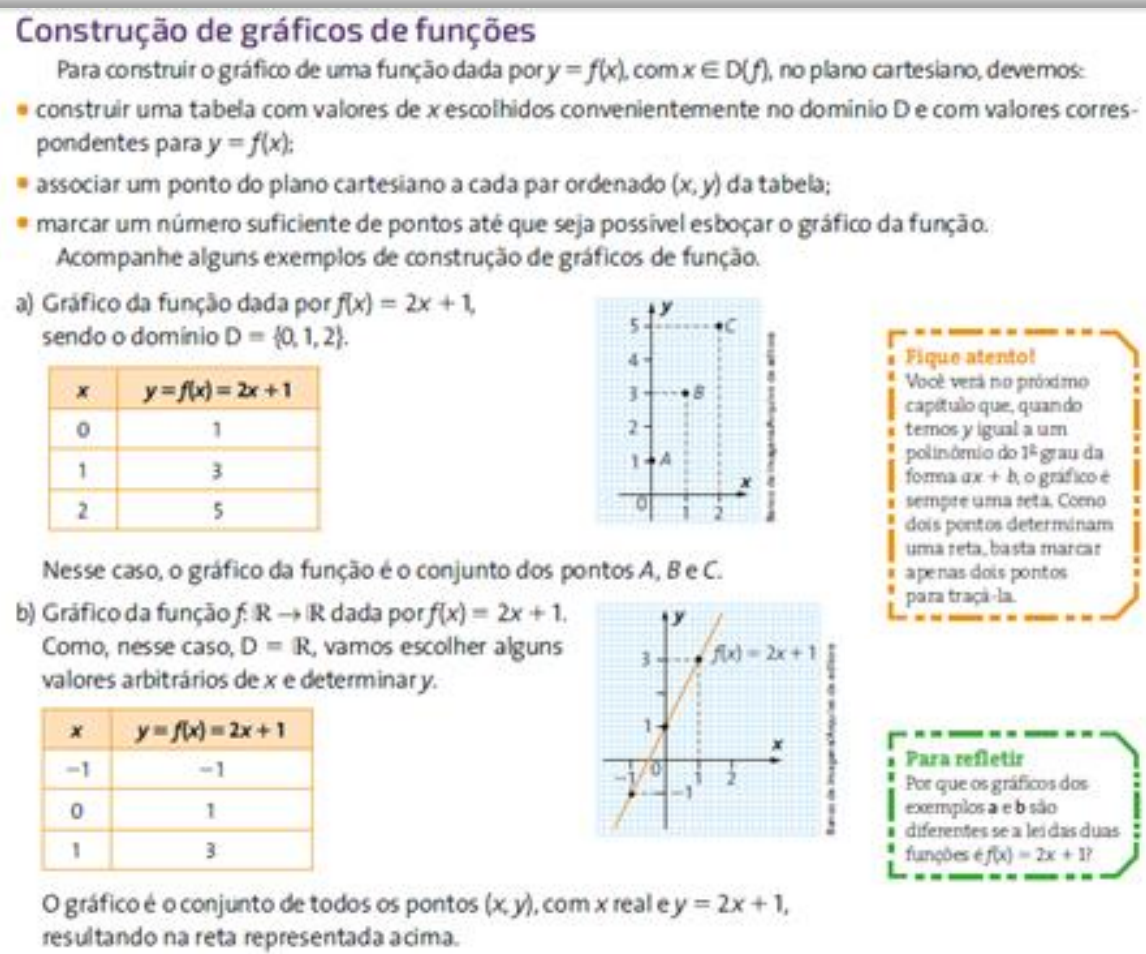

Nesse caso, o gráfico da funçào é o conjunto dos pontos $A, B$ e C.

b) Gráfico da funçàof: $\mathbb{R} \rightarrow \mathbb{R}$ dada por $f(x)=2 x+1$.

Como, nesse caso, $\mathrm{D}=\mathrm{R}$, vamos escolher alguns

valores arbitrários de $x$ e determinary.

\begin{tabular}{|c|c|}
\hline$x$ & $y=f(x)=2 x+1$ \\
\hline-1 & -1 \\
\hline 0 & 1 \\
\hline 1 & 3 \\
\hline
\end{tabular}

O gráficoe o conjunto de todos os pontos $(x, y)$, com $x$ real e $y=2 x+1$, resultando na reta representada acima.

funcos $f(x)=2 x+1$ ?

Figura 6: Exemplo de construção de gráfico (DANTE, 2016, p. 56)

Em seguida, é dada a explicação da determinação do domínio e imagem da função pela linguagem natural, registro gráfico e registro simbólico.

É possivel observar o uso de todos os registros de representação determinados por Almouloud (2007, p. 80): "registro de tabelas, das fórmulas algébricas, gráfico e simbólico". Além desses, o livro usa a linguagem discursiva. Cabe aqui reforçar os argumentos de Duval (2012, p. 270), ao indicar que "a coordenação de muitos registros de representação aparece, 
fundamentalmente, para uma apreensão conceitual de objetos", que nesse caso, são as funções.

A seguir, o autor traz as definições de função crescente, decrescente e constante utilizando linguagem natural com auxílio do registro gráfico. Utiliza também o registro simbólico e de fórmulas algébricas para expressar as particularidades do domínio e da imagem de cada função exemplificada. Ao final do tópico, sintetiza a explicação com definições utilizando linguagem natural, registro simbólico e representação gráfica, conforme ilustrado na Figura 7.

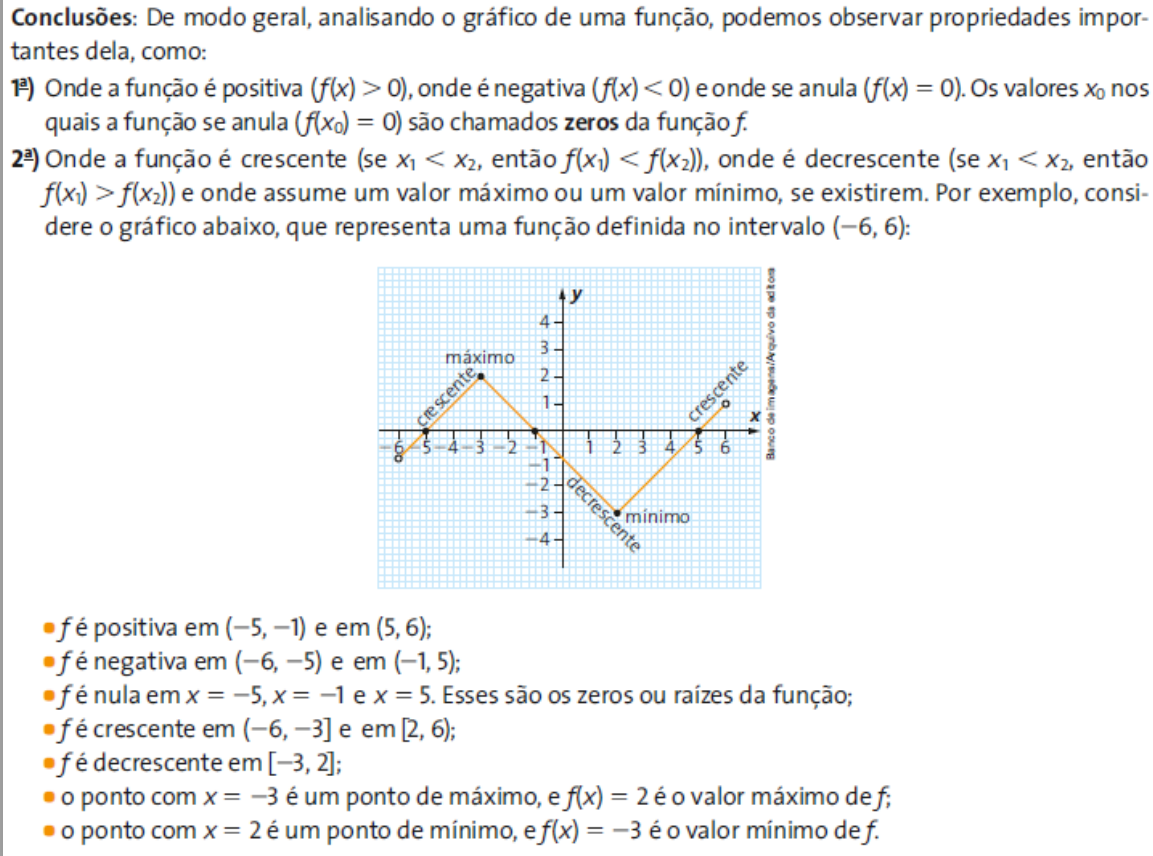

- $f$ é positiva em $(-5,-1)$ e em $(5,6)$;

- $f$ é negativa em $(-6,-5)$ e em $(-1,5)$;

- $f$ é nula em $x=-5, x=-1$ e $x=5$. Esses são os zeros ou raízes da função;

- $f$ é crescente em $(-6,-3]$ e em $[2,6)$;

- $f$ é decrescente em $[-3,2]$;

- o ponto com $x=-3$ é um ponto de máximo, e $f(x)=2$ é o valor máximo de $f$;

- o ponto com $x=2$ é um ponto de mínimo, e $f(x)=-3$ é o valor mínimo de $f$.

Figura 7: Explicação e exemplos sobre o gráfico de uma função (DANTE, 2016, p. 59)

Nesta obra, o autor, ao apresentar a representação gráfica, exprime os detalhes em cada caso, não se resumindo a transcrever os dados de tabelas, possibilitando que o aluno relacione 0 gráfico à explicação em linguagem natural e às tabelas construídas. Fazendo a conversão detalhada entre os registros, o livro permite que o aluno associe diferentes funções aos seus gráficos correspondentes, como sugere as Orientações Educacionais Complementares aos Parâmetros Curriculares Nacionais (BRASIL, 2002).

O autor define função injetiva, sobrejetiva e bijetiva em linguagem natural e as sintetizam na linguagem simbólica. Aborda também com o registro icônico, a partir de diagramas. Traz alguns exemplos que fazem uso predominantemente de linguagem natural, recorrendo também ao registro simbólico, de expressões algébricas, gráfico e icônico. A obra faz uso de três dos registros de representação definidos por Almouloud (2007), além da representação da linguagem natural e 
do registro icônico, realizando a coordenação entre eles, sendo isso algo fundamental para a compreensão do objeto funções.

No último subtítulo, "Função e sequências" o autor relaciona os dois objetos matemáticos com linguagem natural, registro simbólico e expressões algébricas, conforme ilustrado na Figura 8.

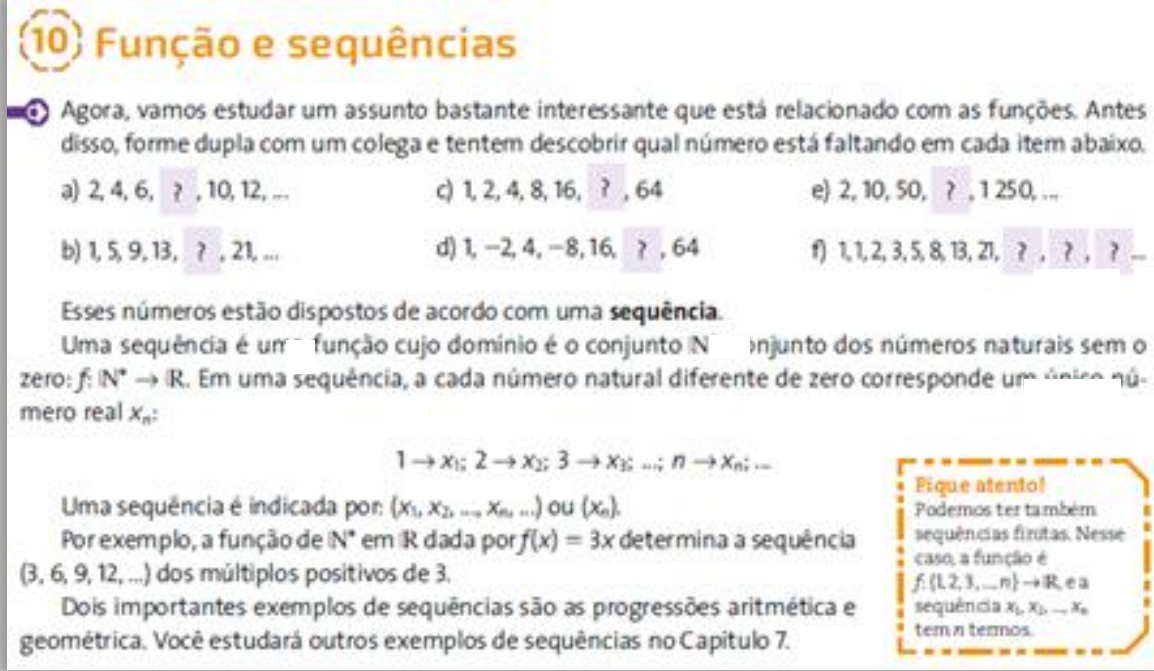
disso, forme dupla com um colega e tentem descobrir qual número está faltando em cada item abaixa.

Figura 8: Relação entre funções e sequências (DANTE, 2016, p. 66)

É introduzido o conceito de progressão aritmética e progressão geométrica a partir de funções, utilizando linguagem natural e exemplos numéricos. Entretanto, não são abordadas as expressões algébricas e nem detalhes de cada progressão, visto que o livro dispõe de um capítulo específico para sequências. Com isso, a obra novamente estabelece relações da Matemática com ela mesma, o que é enfatizado por Gualandi (2016), inserindo conceitos básicos de conteúdos que serão aprofundados no decorrer dos capítulos seguintes.

\section{Considerações}

O Guia do PNLD 2018 esclarece que o conceito de funções no livro analisado "[...] é explorado de modo pertinente, como expressão da relação de dependência entre duas grandezas ou entre elementos de dois conjuntos" (BRASIL, 2017, p. 47). De fato, a noção de funções por meio de conjuntos, representada por diagramas, aparece em quatro dos dez subtítulos que compõe o capítulo: "Um pouco mais de história", "A noção de função por meio de conjuntos", "Domínio, contradomínio e conjunto imagem" e "Função injetiva, sobrejetiva e bijetiva". Em outras cinco seções são utilizadas notações da teoria de conjuntos para definir as situações abordadas, 
como um conjunto pertencente a outro, domínio, imagem e intervalos.

É explicado ainda que "a apresentação do conteúdo é feita por meio de explanações teóricas [...]" e que as "[...] imagens e pequenos textos buscam despertar o interesse dos estudantes pelo que será estudado" (BRASIL, 2017, p. 48). Na presente análise foi possível constatar a proeminência da explicação por meio da linguagem natural, intercalada de exemplos e imagens sobre o assunto. Entretanto, essa representação nunca foi exposta só, contando sempre com o auxílio de outros registros.

Abaixo, a Tabela 1 exprime quantitativamente as ocorrências de cada representação ao longo de capítulo, com exceção da linguagem natural:

Tabela 1: Formas de representação e seu quantitativo

\begin{tabular}{cc}
\hline Representação & Ocorrências \\
\hline Gráfica & 19 \\
Desenho & 3 \\
Tabelas & 08 \\
Expressões algébricas & 32 \\
Icônica & 23 \\
Simbólica & 38 \\
\hline Fonte: Dados da Pesquisa &
\end{tabular}

É possível verificar que o conteúdo de funções presente na obra analisada é contemplado com um número considerável de representações gráficas, de desenhos e icônicas. Em 19, das 22 páginas do capítulo que tratam sobre a explicação do conteúdo, é observada a ocorrência de pelo menos uma dessas representações. Podemos observar que os desenhos geométricos que aparecem no decorrer do capítulo são exibidos com a finalidade de complementar a ideia expressada em língua natural, como por exemplo, quando apresentada a corda de uma semicircunferência na página 41. De forma similar, frequentemente o autor conclui a explicação em língua natural com expressões algébricas e simbólicas. 0 registro em tabelas é usado para associar o domínio ao conjunto imagem, com base em funções expressas pela linguagem natural ou por expressões algébricas. Os gráficos e suas construções são apresentados de maneira que permite 0 aluno diferenciar suas particularidades, inferindo que a mudança na escrita algébrica implica no esboço gráfico, e pode simbolizar coisas distintas, como os exemplos na página 56 , 
que apresentam dois gráficos representados pela mesma expressão algébrica, entretanto, com domínios e imagens diferentes.

A análise de livros didáticos é algo relevante na prática docente. Cabe a ele a escolha dos livros didáticos levando em consideração aspectos subjetivos que são fundamentais em sua prática. Para Duval (2003), o aprendizado matemático implica a capacidade de 0 aluno transitar entre os diferentes registros de representação. Dessa forma, o aluno deve ter contato com os diferentes registros existentes de um mesmo objeto matemático, evitando que ele confunda 0 objeto com sua representação. Assim, na escolha de livros didáticos, é pertinente que o professor analise a forma como os registros aparecem no decorrer da explicação e se ocorrem as conversões entre esses registros, objetivando a compreensão dos objetos matemáticos.

É possível perceber a importância atribuída às diferentes representações semióticas do conteúdo analisado, de forma a proporcionar a coordenação entre os registros apontados. Entretanto, o aprendizado não se resume apenas à leitura e apreciação do conteúdo em livros didáticos. É indispensável a resolução de atividades que contemplem o objeto matemático estudado, de forma a aplicar os saberes adquiridos e aperfeiçoá-los. Por conta da dimensão limitada do trabalho, restringimos nossa análise ao texto explicativo, todavia, compreendemos a importância da investigação de atividades presentes em livros didáticos utilizando a Teoria dos Registros de Representação Semiótica de Raymond Duval, e deixamos a possibilidade da continuação dessa pesquisa em tal área.

\section{Referências}

ALMOULOUD. Saddo Ag. Fundamentos da Didática da Matemática. Curitiba: UFPR, 2007.

BICUDO, Maria Aparecida Viggiani. Meta-análise: seu significado para a pesquisa qualitativa. Revista Eletrônica de Educação Matemática, Florianópolis, v. 9, p. 7-20, 2014.

BRANDL, Eduardo. Funções polinomiais de $1^{\circ}$ e $2^{\circ}$ graus em dois livros didáticos de Matemática sob a perspectiva das representações semióticas. 2011. 81f. Monografia (Especialização em Ensino de Ciências) - Departamento de Educação a Distância. Instituto Federal de Educação, Ciência e Tecnologia de Santa Catarina. Pouso Redondo.

BRASIL. Ministério da Educação. Secretaria da Educação Básica. Orientações Curriculares para o Ensino Médio: Ciências da Natureza, Matemática e suas Tecnologias. v 2. Brasília: MEC/SEB, 2006. 
BRASIL. Ministério da Educação. Secretaria da Educação Média e Tecnológica. PCN+ Ensino Médio - Orientações Educacionais Complementares aos Parâmetros Curriculares Nacionais: Ciências da Natureza, Matemática e suas Tecnologias. Brasília: MEC/SEMT, 2002.

BRASIL. Ministério da Educação. Secretaria de Educação Básica. Guia de Livros Didáticos PNLD 2018: Matemática. Brasília: MEC/SEB, 2017.

BRASIL. Ministério da Educação. Secretaria de Educação Fundamental. Projeto de avaliação dos livros didáticos da $1^{a}$ à $4^{a}$ série. v. 2. Brasília: MEC/SEF, 2003.

COURANT, Richard; ROBBINS, Herbert. O que é Matemática? Tradução de Adalberto da Silva Brito. Rio de Janeiro: Ciência Moderna, 2000.

D'AMORE, Bruno; PINILLA, Martha Isabel Fandiño; IORI, Maura. Primeiros elementos de semiótica: sua presença e importância no processo de ensino-aprendizagem da Matemática. Tradução de Maria Cristina Bonomi. São Paulo: Livraria da Física, 2015.

DANTE, Luiz Roberto. Matemática: Contexto e Aplicações. 3. ed. São Paulo: Ática, 2016.

DUVAL, Raymond. L'analyse cognitive du fonctionnement de la pensée et de l'activitê mathématique: courssur les apprentissages intellectuels donnê à la PUC-SP. São Paulo: PEPGEM/PUC-SP, 1999.

DUVAL, Raymond. Registros de representação semiótica e funcionamento cognitivo da compreensão em Matemática. In: MACHADO, Silvia Dias Alcântara. (Org.). Aprendizagem em Matemática: registros de representação semiótica. Campinas: Papirus, 2003, p. 11-33.

DUVAL, Raymond. Registros de representação semiótica e funcionamento cognitivo do pensamento. Tradução de Méricles Thadeu Moretti. Revista Eletrônica de Educação Matemática, Florianópolis, v. 7, n. 2, p. 266-297, 2012.

GUALANDI, Jorge Henrique. Investigações matemáticas com Grafos para o Ensino Médio. Saarbrucken: Novas Edições Acadêmicas, 2016.

MACHADO, Silvia Dias Alcântara (Org.). Aprendizagem em Matemática: registros de representação semiótica. Campinas: Papirus, 2003.

ROMANATTO. Mauro Carlos. O livro didático: alcance e limites. In: ENCONTRO PAULISTA DE EDUCAÇÃO MATEMÁTICA, 7, 2004, São Paulo. Anais do VII EPEM: Matemática na Escola: conteúdos e contextos. São Paulo: SBEM-SP, 2004, p. 1-2.

TEIXEIRA. Rosane de Fátima Batista. As práticas cotidianas de alfabetização e o livro didático: um estudo etnográfico. 2014. 197f. Tese (Doutorado em Educação) - Setor de Educação. Universidade Federal do Paraná. Curitiba. 